\title{
PET-BT incelenmesi yapılan melanom hastalarının retrospektif analizi
}

\author{
Retrospective analysis of melanoma patients who had undergone \\ PET-CT examination
}

\section{Özgür Bakar, Erkan Vardareli*, Sedef Șahin, Selcen Yüksel**, Tamer Aksoy* \\ Acıbadem Üniversitesi Tıp Fakültesı, Dermatoloji Anabilim Dalı, *Nükleer Tıp Anabilim Dalı, İstanbul, Türkiye **Yıldırım Beyazıt Üniversitesi Tıp Fakültesi, Biyoistatistik Anabilim Dalı, Ankara, Türkiye}

\section{Özet}

Amaç: Tüm dünyada olduğu gibi ülkemizde de melanom insidansı hızla artmaktadır. Evre $1 \mathrm{~b}$ ve üzeri olan melanom hastalarında, metastaz taraması için devlet tarafından geri ödemesi yapılan Pozitron Emisyon Tomografisi-Bilgisayarlı Tomografi (PET-BT) görüntüleme tekniğinin kullanımı da giderek yaygınlaşmışıı. Bu çalışmada PET-BT incelenmesi yapılmış melanom hastalarııı, demografik verileri, klinik bulguları ve tümörlerinin histopatolojik özellikleri araştırılmıştır.

Gereç ve Yöntem: Çalışmaya, 2004-2011 yılları arasında, Nükleer Tıp bölümünde PET-BT incelenmesi yapılan 57 melanom hastasının kayıtlı verileri alınmıştır. Hastalarda, PET-BT pozitifliği esas alınarak, SUV (Standart tutulum değeri), demografik özellikler, Breslow kalınlığı, birincil tümörün tutulum bölgesi, histopatolojik olarak ülserasyon, perinöral, damar ve lenfatik invazyon varlığı, diğer görüntüleme tekniklerinin pozitifliği ile uygulanmıs olan tedavi yöntemleri, retrospektif olarak değerlendirilmiștir.

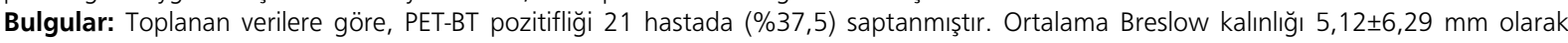
bulunmuştur. Buna göre Breslow kalınlığı raporlanmış hastalar arasında, $\leq 1 \mathrm{~mm}$ olan $\mathrm{n}: 1(\% 7), 2-4 \mathrm{~mm}$ arası olan $\mathrm{n}: 5(\% 36)$ ve >4 mm olan n: 8 (\%57) hastada PET-BT pozitifliği görülmüştür. Breslow kalınlığı ile PET-BT pozitifliği arasında istatistiksel açıdan anlamlı bir ilişki saptanmıştır. Primer tümörlerin vücut tutulum bölgelerine göre dağılımı ise, \%35,3'ü gövdenin sol yarısı, \%25,5'i gövdenin sağ yarısı ve \%39,2'si ise orta hat kökenli olacak şekilde bulunmuştur. Saçlı deri tutulumu olan hastaların hepsinde PET-BT ile uzak metastaz saptanmıştır. Ülserasyon, perinöral, damar ve lenfatik invazyon varlığı ile PET-BT pozitifliğı arasında anlamlı bir ilişki saptanmamıştır. Breslow kalınlığı ile SUV değerleri arasında \%31'lik pozitif korelasyon bulunmuştur. PET-BT ile metastaz saptanan hastaların \%45'inde diğer görüntüleme yöntemleri ile de belirlenmiş metastaz bulguları mevcuttur. Uzak metastazı olan hastaların 2'si hariç hepsine geniş eksizyon ve adjuvan kemoterapi veya radyoterapi tedavi uygulanmıştır.

Sonuç: Yüksek risk grubundaki olguların bir kısmında, tedavi planının oluşturulmasında, konvansiyonel görüntüleme yöntemlerine ilave olarak, PET- BT uygulamasının, önemli bir yeri olduğunu düşünmekteyiz. (Türkderm 2013; 47: 214-7)

Anahtar Kelimeler: Melanom, PET-BT, metastaz

\section{Summary}

Background and Design: Pet positivity was found in 21 (37.5\%) the incidence of melanoma is increasing significantly in Turkey and in the whole world. Thus, Positron Emission Tomography-Computed Tomography (PET-CT), which is being reimbursed by the government for the documentation of metastases of clinically suspicious patients with stages $1 \mathrm{~b}$ and higher, is becoming widely used. This study aims to analyze, the histopathological features of the tumors and the clinical and demographic data on melanoma patients who had undergone PET-CT examination for the screening of metastases.

Materials and Methods: We collected data on 57 melanoma patients who had undergone PET-CT evaluation in the Nuclear Medicine Department between 2004 and 2011. On the basis of PET-CT positivity, we retrospectively analyzed SUV (Standard uptake value), demographic data, Breslow thickness, primary tumor location, presence of histopathologically documented ulceration, perineural, vascular and lymphatic invasion, and metastases detected by other screening methods as well as the proposed treatment modalities.

Results: PET-CT positivity was found in $22(39 \%)$ patients. The mean Breslow thickness was $5.12 \pm 6.29 \mathrm{~mm} ., 1$ patient (\%7) with $\leq 1 \mathrm{~mm}, 5$ (36\%) with $2-4 \mathrm{~mm}$ and 8 patients $(57 \%)$ with $>4 \mathrm{~mm}$ of Breslow thickness had distant metastases. Statistically significant correlation was

Yazışma Adresi/Address for Correspondence: Dr. Özgür Bakar, Acıbadem Üniversitesi Tıp Fakültesı, Dermatoloji Ana Bilim Dalı, İstanbul, Türkiye GSM: +90 5323170351 E-posta: ozgurtimurkaynak@hotmail.com Geliş Tarihi/Received: 17.11.2012 Kabul Tarihi/Accepted: 01.03.2013 


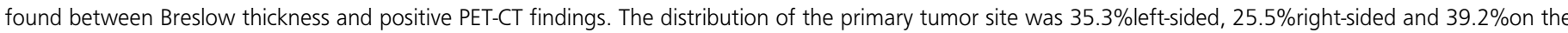

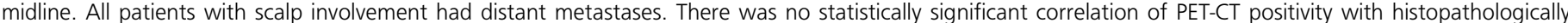

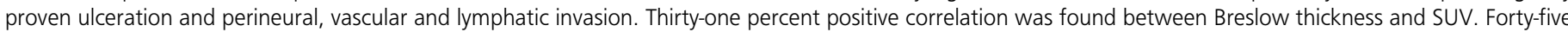

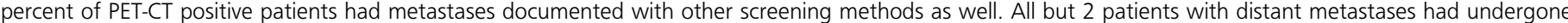
wide tumor resection and adjuvant chemotherapy or radiotherapy.

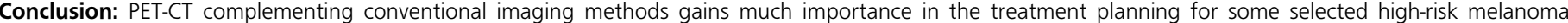
patients (Turkderm 2013; 47: 214-7)

Key Words: Melanoma, PET-CT, metastasis

\section{Giriş}

Melanom insidansı tüm dünyada olduğu gibi ülkemizde de hızla artmaktadır. ${ }^{1}$ BT'nin PET incelemesi tekniğine eklenmiş olması, inceleme yönteminin özgünlüğünü ve özgüllüğünü arttırmıştır. ${ }^{2}$ Ortalama 20-30 dakika içerisinde servikal bölge, göğüs, abdomen, pelvis ve uyluk bölgesi standart incelemesi yapılabilmektedir. Bu nedenle, bu görüntüleme tekniğinin kullanımı, metastaz açısından klinik şüphesi olan Evre $1 \mathrm{~b}$ ve üzeri melanom hastalarında giderek yaygınlaşmıştır.3,4 Kurumumuzun 2004 yılından günümüze PET incelenmesi açısından referans hastanelerden biri olma özelliğini göstermesi nedeniyle, son 7 yıl içindeki sevk edilen melanom hastalarının kayıtlarını retrospektif olarak incelemeyi uygun gördük.

\section{Gereç ve Yöntem}

2004-2011 yılları arasında, Nükleer Tıp Bölümü'ne, PET-BT incelenmesi için başvuran hastaların elektronik ve dosya kayıtları incelenmeye alınmıştır. PET-BT pozitifliği esas alınarak, standart tutulum değeri (SUV), demografik özellikleri, Breslow kalınlığı, birincil tümörün tutulum bölgesi, histopatolojik olarak ülserasyon, perinöral, damar ve lenfatik invazyon varlığı, diğer görüntüleme tekniklerinin pozitifliği ile uygulanan tedavi yöntemleri retrospektif olarak değerlendirilmiştir.

\section{istatistiksel yöntemler}

Bu çalışmada SPSS 20.0 paket programı kullanılarak çalışmanın hipotezleri test edilmiştir. Tanımlayıcı istatistik olarak normal dağılım gösteren sürekli değişkenler için ortalamaıstandart sapma; normal dağılım göstermeyen değişkenler için ortanca(minimummaksimum) değerleri verilmiştir. Kategorik değişkenler için sayı ve yüzdelerden yararlanılmıştır. İki kategorik değişken arasındaki ilişkinin incelenmesinde Ki-kare test istatistiği kullanılmıştır. Bağımsız iki grup karşılaştırmalarında Mann-Whitney $U$ test istatistiği kullanılmıştır. Spearman's Rho korelasyon katsayısı kullanılarak sürekli değişkenler arasındaki ilişki incelenmiştir. Bu çalışmadan elde edilen yaş ortalaması ile literatür bilgisi arasında istatistiksel olarak fark olup olmadığı evren ortalaması önemlilik testi ile değerlendirilmiştir. Tüm istatistiksel analizler için Tip-ı hata oranı $\alpha=0,05$ olarak alınmıştır.

\section{Bulgular}

\section{Demografik özellikler}

Çalışmada 32 erkek (\%56) ve 25 kadın (\%44) olmak üzere 57 melanom hastası değerlendirilmiştir. 47 hasta (\%82) Türk, 10’u (\%18) ise yabancı uyrukludur. Hastaların yaşları 19-94 arasında olup ortalama $52,2 \pm 16,7^{\prime}$ dir.

\section{Klinik özellikler}

Kayıtları incelenen 57 hastadan 51'inde birincil tümör tutulum alanı bildirilmiştir. Buna göre tutulum alanları 18 hastada gövde $(\% 35,3)$, $15^{\prime}$ inde alt ekstremite $(\% 29,4), 7$ 'sinde üst ekstremite $(\% 13,7)$, 10 'unda ise baş boyun $(\% 19,6), 1^{\prime}$ 'inde ise mukozal ( $\% 2$ ) bölgesindedir. Bunların ise $18^{\prime} \mathrm{i}(\% 35,3)$ sol, 13'ü $(\% 25,5)$ sağ, 20'si $(\% 39,2)$ ise orta hat kökenlidir.

PET-BT pozitifliği 13'ü erkek $(\% 61,9)$, 8'i kadın $(\% 38,1)$ olmak üzere toplam 21 hastada $(\% 37,5)$ saptanmıştır. PET-BT pozitifliği ile cinsiyet arasındaki ilişki istatistiksel olarak anlamlı değildir $(p>0,05)$. Ortanca standart tutulum değeri (SUV) 0'dır (min: 0-mak: 22,39).

Metastaz saptanan 22 hastanın 19'unun birincil tümörlerinin tutulum bölgesi ve PET-BT ile saptanmış metastaz bölgeleri raporlanmıştır. Buna göre 8'i (\%42) gövdenin sol yarısı, 2'si (\%11) gövdenin sağ yarısı ve 9'u (\%47) ise orta hat kökenlidir (Resim 1 a,b). Metastaz bölgeleri, 10 hastada tek başına lenf nodu, 2 hastada deri ve lenf nodu, 5 hastada çoklu organ, 1 hastada sadece kemik ve 1 hastada yine sadece karaciğer şeklinde tespit edilmiştir (Resim 2 a,b). Saçlı deri tutulumu olan 4 hastanın hepsinde PET-BT ile uzak metastaz saptanmıştır.

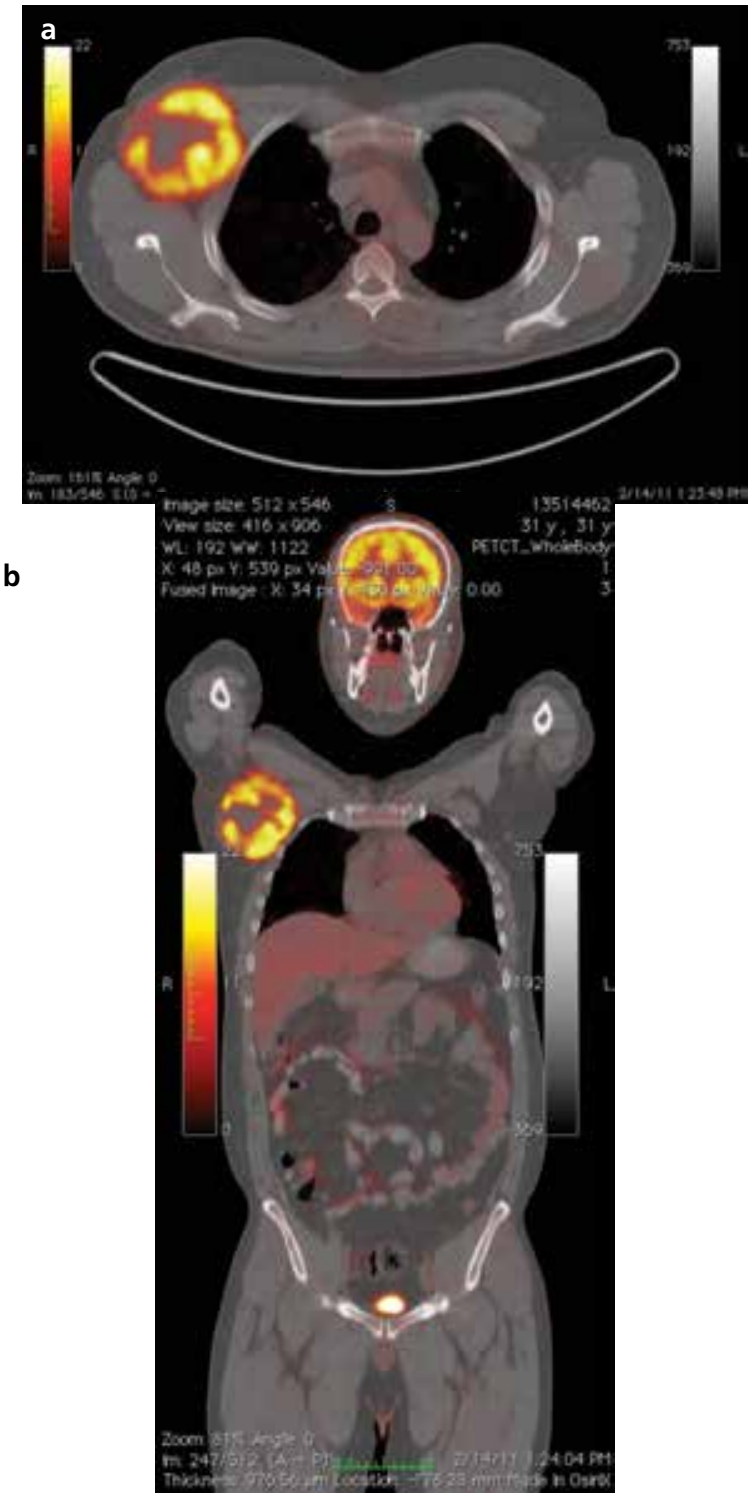

Resim 1-a,b. Aksiller lenf nodlari ve pektoral kasın PET-BT tutulumları. 


\section{Histopatolojik özellikler}

Breslow kalınlık kaydı olan toplam 14 hastanın ortalama tümör kalınlığ $5,12 \pm 6,29 \mathrm{~mm}$ olarak bulunmuştur. Tümör kalınlığı ortalaması $\pm s t a n d a r t$ sapması PET-BT pozitif olan hastalarda 5,42 $\pm 3,37$ PET-BT negatif hastalarda $4,68 \pm 7,07$ 'dir. PET-BT pozitif ve negatif hasta gruplarında tümör kalınlığ ortalamaları arasındaki fark istatistiksel olarak anlamlı bulunmamıştır $(p>0,05)$. Histopatolojik olarak ülserasyon saptanan 22 hastanın 9'unda (\%41), perinöral invazyon saptanan 6 hastanın 3'ünde (\%50), damar invazyonu saptanan 6 hastanın 3 'ünde (\%50), enfatik invazyon saptanan 8 hastanın 3'ünde $(\% 37,5)$ PET-BT pozitifliği bulunmaktadır. PET-BT pozitifliği ile ülserasyon, perinöral invazyon, damar invazyonu, lenfatik invazyon saptanma oranları arasındaki ilişki istatistiksel olarak anlamlı saptanmamıştır ( $p>0,05)$ (Tablo 1) Histopatolojik değerlendirmeler arasında ülserasyon saptanan grupta olmayan gruba göre Breslow kalınlığı açısından fark istatistiksel olarak anlamlı bulunmuştur $(p=0,002)$. Aynı şekilde lenfatik invazyon saptanan grupta olmayan gruba göre Breslow

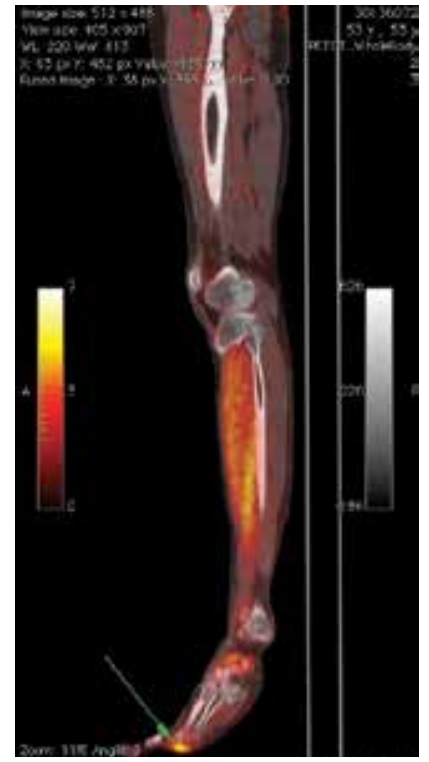

Resim 2a. Ayak altında primer tümöre ait tutulum

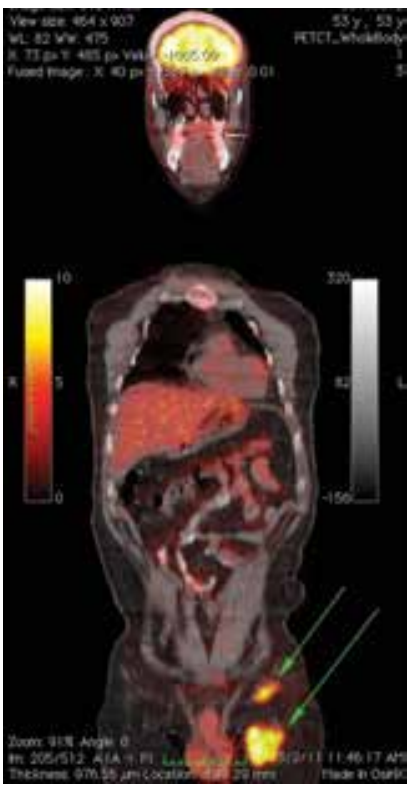

Resim 2b. İnguinal ve femoral lenf nodlarının metastatik tutulumu kalınlığı açısından fark istatistiksel olarak anlamlı olarak bulunmuştur $(p=0,028)$, (Tablo 2). Breslow kalınlığı ile SUV arasında \%31'lik pozitif bir korelasyon bulunmuş ve bu korelasyon istatistiksel olarak anlamlı olarak değerlendirilmiştir $(p=0,040)$ (Tablo 2).

\section{Diğer inceleme yöntemleri}

PET-BT ile metastaz saptanan 22 hastanın 10'unda (\%45), inceleme öncesi ultrasonografi, manyetik rezonans (MR) ve bilgisayarlı tomografi (CT) gibi diğer görüntüleme yöntemleri ile de belirlenmiş metastaz bulguları mevcuttur.

\section{Tedavi seçimi}

Metastaz saptanan 22 hastanın 2'si dışındaki tüm hastalara geniş eksizyon ve adjuvan kemoterapi veya radyoterapi tedavi uygulanmıştır.

\section{Tartışma}

PET-BT incelemesi tekniğinin kullanım alanı tüm dünyada olduğu gibi ülkemizde de giderek yaygınlaşmıştır. ${ }^{1}$ Devlet tarafından Evre $1 \mathrm{~b}$ melanom hastalarında metastaz taraması için geri ödeme yapılması kullanım sıklığını arttıran faktörlerden biridir. ${ }^{5}$

\begin{tabular}{|c|c|c|}
\hline \multirow[b]{2}{*}{ Ülserasyon } & \multicolumn{2}{|c|}{ Pet-BT } \\
\hline & Pozitif & Negatif \\
\hline var & 9 & 13 \\
\hline \multirow[t]{2}{*}{ yok } & 4 & 16 \\
\hline & \multicolumn{2}{|c|}{$\chi^{2}=2,143 ; p=0,190$} \\
\hline Perinöral invazyon & pozitif & negatif \\
\hline var & 3 & 3 \\
\hline \multirow[t]{2}{*}{ yok } & 9 & 23 \\
\hline & \multicolumn{2}{|c|}{$\chi^{2}=1,119 ; p=0,357$} \\
\hline Damar invazyonu & pozitif & negatif \\
\hline var & 3 & 3 \\
\hline \multirow[t]{2}{*}{ yok } & 9 & 26 \\
\hline & \multicolumn{2}{|c|}{$\chi^{2}=1,459 ; p=0,227$} \\
\hline Lenfatik invazyon & pozitif & negatif \\
\hline var & 3 & 5 \\
\hline \multirow[t]{2}{*}{ yok } & 9 & 23 \\
\hline & \multicolumn{2}{|c|}{$\chi^{2}=0,268 ; p=0,605$} \\
\hline
\end{tabular}

Tablo 2. Histopatolojik özelliklerin alt grupları ve PETBT tutulumu ile Breslow kalınlıklarının karşılaştırılması

\begin{tabular}{|l|l|l|l|c|}
\hline & \multicolumn{4}{|c|}{ Breslow kalınlığı } \\
\hline Ülserasyon & Ortanca & Minimum & Maksimum & p \\
\hline var & 4 & 1,70 & 30 & 0,002 \\
\hline yok & 1,84 & 0,43 & 15 & \\
\hline Perinöral invazyon & & & & \\
\hline var & 6,875 & 2 & 12 & 0,086 \\
\hline yok & 3,40 & 0,43 & 30 & \\
\hline Damar invazyonu & & & & \\
\hline var & 7,55 & 2 & 12 & 0,060 \\
\hline yok & 2,86 & 0,43 & 30 & \\
\hline Lenfatik invazyon & & & & \\
\hline var & 8,5 & 2 & 30 & 0,008 \\
\hline yok & 2,7 & 0,43 & 30 & \\
\hline PET-BT & & & & \\
\hline pozitif & 4,2 & 0,75 & 12 & 0,028 \\
\hline negatif & 2,5 & 0,43 & 30 & \\
\hline
\end{tabular}


Bu çalışmada \%18'i yabancı uyruklu olmak üzere toplam 57 melanom hastasının kayıtlı verilerine ulaşıımıştır. Hastaların \%56'sı erkek olarak saptanmıştır. Erkek cinsiyette saptanan bu sınırda fazlalık, diğer kanserlerde de olduğu gibi erkeklerdeki tümör insidansının daha fazla olması ile uyumlu olarak değerlendirilmiştir. Literatürde belirtilen ortalama tanı koyma yaşı $55,7^{\prime}$ dir6 . Bu çalışmada elde edilen 52,15 yaş ortalaması ile literatür bilgisi arasında istatistiksel olarak fark yoktur $(p>0,05)$.

En önemli prognostik belirteç olan Breslow kalınlığı, hastalarda ortalama $5,12 \pm 6,29 \mathrm{~mm}$ olarak belirlenmiş olup, bu hastaların \%39'unda ise bölgesel ve/veya uzak metastaz saptanmıştır. Breslow kalınlığı $1 \mathrm{~mm}$ altında olduğunda, eski kılavuzlara göre nodal tutulum beklenmezken, güncel kılavuzlarda özellikle belli özellikleri taşıyan $(0,75-0,99 \mathrm{~mm}$ ve ülsere, ve/veya mitoz hızı $\geq 1 / \mathrm{mm}^{2}$ ) ince melanomlarda $\% 20$ oranında tutulum olabileceği vurgulanmıştır.(7) Kendi kayıtlarımızda da ince (Breslow kalınlığı $1 \mathrm{~mm}$ ) melanomu olan 1 hastada PET-BT incelenmesi ile bölgesel metastaz saptanmıştır. Ana tümörün tutulum bölgesine bakılacak olduğunda ise; gövde $(\% 35,3), 15^{\prime}$ inde alt ekstremite $(\% 29,4), 7$ 'sinde üst ekstremite $(\% 13,7), 10$ 'unda ise baş boyun (\%19,6), 1 'inde ise mukozal (\%2) oranlarında tutulmuştur. Yakın zamanda bazı çalışmalarda da değinildiği gibi kendi hastalarımızda da bu bölge çoğunlukla orta hat ve sol taraf olarak bulunmuştur8-9

Saçlı deri ve boyun melanomlarında diğer vücut tutulum alanlarına göre beklenen 5 yıllık sağ kalım oranı düşüktür ${ }^{10}$. Bu bilgiyle uyumlu olarak, saptanan 4 saçlı deri melanom hastasının tamamında uzak metastaz saptanmıştır. Uzak metastazların erken saptanması ile nükssüz sağ kalım süresini uzatabileceği gösterilmiş olan adjuvan tedavilerin de erken başlanabilmesi mümkün olmaktadır11. Kendi hastalarımızda da metastaz saptanan 22 hastanın 2'si dışındakilere bu yolla adjuvan kemoterapi veya radyoterapi başlanmıştır.

Ülserasyon, perinöral invazyon, damar ve lenfatik invazyon gibi özelliklerin patoloji raporlarında belirtilmesinin önemi, bu özellikleri gösteren hastalarda \%14-67 arası değişen oranlarda uzak metastaz saptanması ile gösterilmiştir. Ancak bu çalışmada, PET-BT pozitifliği ile ülserasyon, perinöral invazyon, damar invazyonu, lenfatik invazyon saptanma oranları arasındaki ilişki istatistiksel olarak anlamlı saptanmamıştır. Bu bulgunun daha geniş hasta serilerinde prospektif olarak değerlendirilmesi gerektiğini düşünmekteyiz.

PET-BT incelenmesi birçok tümörde metastaz taramasında yaygın olarak kullanılmasına karşıık güncel verilere göre bazı avantajları ve bazı dezavantajlara sahiptir12. Yüksek riskli melanom hastalarında nodal hastalık saptanmasında pozitif prediktif değeri ve uzak metastaz saptanmasında negatif prediktif değeri yüksek bulunmuş, bazı çalışmalarda ise MR ile karşılaştııılığında pulmoner ve hepatik metastazların saptanmasında MR inceleme tekniğinin PET-BT'den daha üstün olduğu savunulmuştur12-14. Ameliyat öncesi dönemde, erken evre deriye sınırlı melanomlarda, PET-BT incelenmesi ile yalancı pozitiflikler saptanabileceğinden, hastalarda gereksiz endişelere neden olmamak için bu tekniğin uygulanması önerilmemektedir ${ }^{11}$.Yine dört görüntüleme yöntemini (PET-BT, ultrasonografi, MR ve BT) karşılaştıran bir başka çalışmada ise ultrasonografinin, lenf nodu metastazı saptamada en yüksek özgünlük ve özgüllüğe ve en yüksek prediktif değere sahip olduğu bunun yanında ise uzak metastazların saptanmasında PET-BT'nin en yüksek özgüllüğe sahip olduğu belirtilmiş̧ir.2 Bu çalışmada, PET- BT ile metastaz belirlenen olguların yalnızca \%45'inde diğer yöntemlerle de saptanmış metastaz bulgusu bulunmuş, \%55'inde ise tek başına PET- BT metastatik tutulum bilgisi edinilmiştir.

Sonuç olarak, düşük risk grubundaki melanom hastaları için, evrelendirme ve takiplerde görüntüleme yöntemleri artık fazla yer bulmamaktadır. Yüksek risk grubundakilerde ise, klinik bulgular göz önünde bulundurularak, uygun yöntemin hastaya göre akılcı olarak seçilmelidir. Yüksek risk grubundaki bu olguların bir kısmında ise, özellikle tedavi planının oluşturulmasında, konvansiyonel görüntüleme yöntemlerine ilave olarak, PET- BT uygulaması önemli bir yer edinmiştir. Bu çalışmada da saptanan, SUV ve Breslow kalınlıklığı arasındaki \%31'lik korelasyon, yüksek risk grubundaki melanom hastalarında PETBT uygulamasının önemini desteklemektedir.

Ayrıca ciddi bir sağlık sorunu olan melanomun epidemiyolojisi, tanı ve tedavisi ile ilgili yapılması planlanan çalışmalarda ilgili bilim dalları ile işbirliği içinde bulunmak, söz konusu hastalık ile ilgili güncel kılavuzları paylaşıp, hasta kayıtlarının düzenli tutulmasını sağlamak, veri kayıplarını engelleyecek ve hasta için en uygun olan takip ve tedavi şemasının belirlenmesini sağlayacaktır.

\section{Kısaltmalar}

PET-BT: Pozitron Emisyon Tomografisi- Bilgisayarlı Tomografi PET-CT: Positron Emision Tomography- Computed Tomography BT: Bilgisayarlı Tomografi

MR: Manyetik Rezonans

SUV: Standart tutulum değeri

\section{Kaynaklar}

1. Özçelik S, Akyol M: Melanoma Epidemiyolojisi. Turkderm 2007;41(Özel Sayı 2): 1-5.

2. Xing $Y$, Cromwell KD, Cormier JN: Review of Diagnostic Imaging Modalities for the Surveillance of Melanoma Patients. Dermatol Res Pract 2012; 2012: 941 21.

3. Singh $\mathrm{B}$, Ezziddin S, Palmedo $\mathrm{H}$, et al: Preoperative 18F-FDG-PET/CT imaging and sentinel node biopsy in the detection of regional lymph node metastases in malignant melanoma. Melanoma Res 2008;18:346-52.

4. Krug B, Crott R, Lonneux M, Baurain JF, Pirson AS. Vander Borght T: Role of PET in the initial staging of cutaneous malinant melanoma: systematic review. Radiology 2008;249:836-44.

5. Mudun A: Türkiye'de PET Görüntülemenin Durumu. Turk J Nucl Med 2008;17:1-9.

6. Bradford PT, Anderson WF, Purdue MP, Goldstein AM, Tucker MA: Rising melanoma incidence rates of the trunk among younger women in the United States. Cancer Epidemiol Biomarkers Prev 2010;19:2401-6.

7. Wong SL, Balch CM, Hurley P, et al: Sentinel lymph node biopsy for melanoma: american society of clinical oncology and society of surgical oncology joint clinical practice guideline. J Clin Oncol 2012;30:2912-8.

8. Butler ST, Fosko SW: Increased prevalence of left-sided skin cancers. J Am Acad Dermatol 2010;63:1006-10.

9. Bulliard $\mathrm{J}$, Levi $\mathrm{F}$ : Left-sided excess of melanoma occurrence but not of other skin cancers: additional evidence. J Am Acad Dermatol 2011;65:206-7.

10. de Giorgi V, Rossari S, Gori A, Grazzini M, Savarese I, Crocetti E, et al: The prognostic impact of the anatomical sites in the 'head and neck melanoma': scalp versus face and neck. Melanoma Res 2012;22:402-5.

11. Garbe C, Peris K, Hauschild A, et al: Diagnosis and treatment of melanoma European consensus-based interdisciplinary guideline - Update 2012. Eur J Cancer 2012;48:2375-90

12. Buck AK, Herrmann K, Stargardt T et al: Economic Evaluation of PET and PET/ CT in Oncology: Evidence and Methodologic Approaches. J Nucl Med Technol 2010;38:6-17.

13. Dellestable P, Granel-Brocard F, Rat AC, et al: Impact of whole body magnetic resonance imaging $(\mathrm{MRI})$ in the management of melanoma patients, in comparsion with positron emission tomography/computed tomography (PET/ CT) and CT. Ann Dermatol Venereol 2011;138:377-83.

14. Wagner T, Chevreau C, Meyer N, et al: Routine FDG PET-CT in patients with highrisk localized melanoma has a high predictive positive value for nodal disease and high negative predictive value for the presence of distant metastases. J Eur Acad Dermatol Venereol 2012;26:1431-5. 